\title{
Composição Químico-Bromatológica, Produção de Gás, Digestibilidade in Vitro da Matéria Seca e NDT Estimado da Silagem de Sorgo com Diferentes Proporções de Panículas ${ }^{1}$ \author{
Tilemahos Zervoudakis ${ }^{2}$, Odilon Gomes Pereira ${ }^{3}$, Rafael Gonçalves Veloso ${ }^{5}$
} \\ Luciano da Silva Cabral ${ }^{2}$, Sebastião de Campos Valadares Filho ${ }^{3}$, Edenio Detmann ${ }^{4}$, Joanis
}

\begin{abstract}
RESUMO - Foram objetivos do presente trabalho avaliar as alterações na composição bromatológica, nas frações nitrogenadas e de carboidratos, estimar a taxa de digestão dos carboidratos fibrosos (CF) e não-fibrosos (CNF), determinar a digestibilidade in vitro da matéria seca (DIVMS) e estimar o NDT da silagem de sorgo com as seguintes proporções de panículas: 0, 20, 40, 60, 80 e 100\%. Foram determinados os teores de matéria seca (MS), proteína bruta (PB), extrato etéreo (EE), matéria mineral (MM), fibra em detergente neutro (FDN), as frações protéicas: NNP, $\mathrm{B}_{1}+\mathrm{B}_{2}, \mathrm{~B}_{3}$ e $\mathrm{C}$, e os carboidratos não fibrosos (CNF) e as frações $\mathrm{B}_{2}$ e $\mathrm{C}$ dos carboidratos totais. As taxas de digestão das frações dos carboidratos totais foram estimadas por meio da técnica de produção de gás, a digestibilidade in vitro da matéria seca (DIVMS) pela técnica de dois estágios e o NDT estimado pela composição bromatológica. O acréscimo de panículas à silagem de sorgo aumentou linearmente os teores de MS, PB, CNF, EE e lignina na FDN e, reduziu os teores de MM e FDN. O NNP e as frações B1+B2, $B_{3}$ e C variaram de 9,19 a 21,24, de 67,63 a 75,98, de 3,85 a 6,09 e de 5,09 a 10,98\% do $\mathrm{N}$ total. Os teores dos CNF aumentaram linearmente e da fração $\mathrm{B}_{2}$ dos carboidratos totais foram reduzidos, os quais variaram de 208,18 a 564,07 e de 381,29 a zero $\mathrm{g} / \mathrm{kg}$ de MS, respectivamente. As taxas de digestão dos CNF e da fração $\mathrm{B}_{2}$ variaram de 0,1358 a $0,1563 \mathrm{~h}^{-1}$ e de 0,0247 a $0,0294 \mathrm{~h}^{-1}$. O volume final de gás não foi influenciado pela adição de panículas e a DIVMS máxima de $69,52 \%$ foi obtida com $60,10 \%$ de panículas. Embora o NDT estimado tenha aumentado linearmente, considerando a não alteração da produção de gás e o comportamento quadrático da DIVMS, pode-se inferir que a utilização destas estimativas não parece adequada.
\end{abstract}

Palavras-chave: cinética, digestão, frações protéicas e carboidratos

\section{Chemical Composition, Gas Production, In Vitro Dry Matter Digestibility and TDN Estimate of Sorghum Silage with Different Panicle Proportions}

\begin{abstract}
This work had as objective to evaluate the chemical composition alteration in the nitrogen and carbohydrate fractions, to estimate the digestion rate of fiber carbohydrates (FC) and non-fiber carbohydrates (NFC), to determine the in vitro dry matter digestibility (IVDMD) and to estimate the TDN of sorghum silage with different panicle proportions $(0,20,40,60$, 80 and $100 \%)$. The contents of dry matter (DM), crude protein (CP), ether extract (EE), ash, neutral detergent fiber (NDF), nitrogen fractions: NPN, B1+B2, $B_{3}$ and $C$, non-fiber carbohydrate (NFC) and $\mathrm{B}_{2}$ and $\mathrm{C}$ fractions of total carbohydrates were determined. The digestion rates of the NFC and $\mathrm{B}_{2}$ fractions of total carbohydrates were estimated by in vitro gas production technique, the IVDMD was determined by two-stage technique and TDN, by chemical composition. The increase in the panicle in sorghum silage increased linearly the amounst of DM, CP, NFC, EE and lignin in NDF and reduced the ash and NDF amount. The NPN and the $\mathrm{B} 1+\mathrm{B} 2, \mathrm{~B} 3$ and $\mathrm{C}$ fractions ranged from 9.19 to 21.24 , from 67.63 to 75.98 , from 3.85 to 6.09 and from 5.09 to $10.98 \%$ of total $\mathrm{N}$. The NFC amount increased linearly and of the $\mathrm{B}_{2}$ fraction of total carbohydrates reduced by addition of panicle, ranging from 208.18 to 564.07 and from 381.29 to $0 \mathrm{~g} / \mathrm{kg}$ of DM, respectively. The digestion rate of $\mathrm{NFC}$ and $\mathrm{B}_{2}$ fraction ranged from 0.1358 to $0.1563 \mathrm{~h}^{-1}$ and from 0.0247 to $0.0294 \mathrm{~h}^{-1}$. The total gas production was not influenced by panicle addition and the maximum IVDMD of $69.52 \%$ was obtained with $60.10 \%$ of panicle. Althought the estimated TDN had increased linearly, considering the no alteration of gas production and the quadratical effect of IVDMD, it can be suggested that the utilization of these estimates are not correct.
\end{abstract}

Key Words: digestion, kinetic, carbohydrate and protein fractions

\footnotetext{
${ }^{1}$ Parte da tese apresentada à UFV para obtenção do título "Doctor Scientiae".

2 Professor da UFMT. E.mail: cabralls@bol.com.br

3 Professor do DZO-UF.V E.mail: scvfilho@mail.ufv.br

4 Professor da UENF.

5 Estudante de graduação, DZO-UFV.
} 


\section{Introdução}

A produção de ruminantes no Brasil baseia-se na utilização das gramíneas tropicais como principal fonte de nutrientes. Estas gramíneas diferenciam-se das de clima temperado $\left(\mathrm{C}_{3}\right)$ quanto à eficiência de fixação de carbono, o que as confere maior produção de massa seca por unidade de área. A maior eficiência destas gramíneas é o resultado da utilização da rota de fixação de carbono por intermédio da enzima fosfoenolpiruvato carboxilase. Esta enzima foi desenvolvida durante a evolução destas plantas nos ambientes tropicais, como meio de reduzir a fotorespiração, verificada em plantas $\mathrm{C}_{3}$, devido à elevada afinidade da enzima ribulose 1,5 bifosfato carboxilase-oxigenase por $\mathrm{O}_{2}$ em elevadas temperaturas, uma vez que a taxa de fotorespiração é inversamente proporcional à eficiência fotossintética (Lehninger et al., 1993; Brock et al., 1994).

Entretanto, devido à estacionalidade na sua produção, o desempenho dos animais é relativamente baixo, em razão da redução qualitativa e quantitativa de massa verde nos pastos na época seca do ano. Dessa forma, o armazenamento do excedente de forragem oriundo do período das águas torna-se uma estratégia de suma importância para contornar os problemas nutricionais na época seca.

Neste contexto, a ensilagem tem grande importância na conservação dos alimentos, cujo valor nutricional é função da qualidade do material ensilado, bem como das técnicas de ensilagem empregadas. Entretanto, devido ao elevado teor de umidade das gramíneas tropicais, a qualidade destas silagens tem sido limitada pela resistência à queda do $\mathrm{pH}$ da massa ensilada, condição primordial para conservação do material.

Com base nisso, a confecção de silagens de milho aumentou drasticamente nas últimas décadas, uma vez que os grãos contidos nas espigas proporcionam tanto o aumento do teor de matéria seca, quanto o aumento do valor nutricional da silagem, devido ao acréscimo de carboidratos não fibrosos.

Na mesma proporção, a utilização de sorgo para a ensilagem vem aumentando no Brasil, basicamente em função da também elevada produção de massa seca, da possibilidade de utilização da rebrota que pode atingir até $60 \%$ da produção do primeiro corte, pela sua maior tolerância à seca e a elevadas temperaturas e por não ser utilizado na alimentação humana (Zago, 1989).

R. Bras. Zootec., v.32, n.5, p.1250-1258, 2003
Considerando que os carboidratos não fibrosos (CNF) apresentam disponibilidade nutricional rápida e completa no trato gastrintestinal dos ruminantes, ao contrário dos carboidratos fibrosos (CF), (Van Soest, 1967; Mertens, 1996), a confecção de silagens de sorgo com maiores teores de panículas (grãos), teoricamente poderia aumentar o valor nutricional do material ensilado. Entretanto, para o sorgo, cuidados devem ser tomados na escolha das variedades de plantas com baixo teor de taninos.

Segundo Van Soest (1994), os taninos são quaisquer compostos fenólicos de suficiente peso molecular, os quais contêm hidroxilas o bastante para formar fortes complexos com proteínas e outras moléculas, sintetizados em certas espécies de plantas como fatores de proteção contra a predação por herbívoros. Dos efeitos dos taninos, destacam a capacidade de inibir a atividade de certas enzimas e seus efeitos tóxicos contra certos grupos de bactérias ruminais, especialmente as celulolíticas (Van Soest, 1994).

Dessa forma, o presente trabalho foi conduzido com os objetivos de determinar as alterações na composição químico-bromatológica e nas frações protéicas e de carboidratos, determinar as taxas de digestão das frações de carboidratos e avaliar o valor nutricional de silagens de sorgo com diferentes proporções de panículas, por meio da técnica de produção de gases e da digestibilidade in vitro da matéria seca, e estimar o teor em nutrientes digestíveis totais (NDT).

\section{Material e Métodos}

O sorgo (Sorghum vulgare, L.), híbrido AG 2002, utilizado neste estudo foi cultivado em área do Departamento de Zootecnia da UFV-MG, cujo plantio foi realizado em outubro de 1998 de acordo com as recomendações do produtor de sementes. Como adubação de plantio, foram aplicados $300 \mathrm{~kg} / \mathrm{ha}$ de 8-2816 (N-P-K) e, como adubação de cobertura, aos $25 \mathrm{e}$ 45 dias de plantio, $150 \mathrm{~kg} / \mathrm{ha}$ da mistura $20-0-20$ e $100 \mathrm{~kg} / \mathrm{ha}$ de uréia, respectivamente.

A colheita foi realizada de forma manual, por meio de um facão, à aproximadamente $10 \mathrm{~cm}$ do solo, quando os grãos atingiram o estádio farináceo-duro (118 dias), sendo as plantas em seguida, conduzidas ao laboratório de animais do DZO. Trinta plantas foram tomadas aleatoriamente, as quais foram separadas em duas partes: colmo+folhas e panículas, para determinação da proporção de cada parte na planta 
inteira. Em seguida, cada parte (colmo+folha e panículas) foi picada separadamente, proporcionando partículas com tamanho médio variando de 2 a $4 \mathrm{~cm}$, e ensilada em silos laboratoriais de PVC, de $40 \times 10 \mathrm{~cm}$, dotados de válvula de Bunsen, nas proporções de 0 , 20, 40,60, 80 e 100\% de panículas (\% na matéria natural), com três repetições, em um delineamento inteiramente casualizado. Considerando as dimensões dos silos e que estes acondicionaram, em média, $1,96 \mathrm{~kg}$ de matéria natural, a compactação aproximada é de $600 \mathrm{~kg} / \mathrm{m}^{3}$, a qual foi realizada por intermédio de um compactador manual de madeira.

Os silos foram abertos um mês após a ensilagem e, para determinação dos compostos nitrogenados não-protéicos (NNP) nas amostras frescas, cerca de $10 \mathrm{~g}$ de silagem foram pesados em becker de $500 \mathrm{~mL}$, bem como adicionados $100 \mathrm{~g}$ de água destilada. $\mathrm{O}$ material ficou em repouso por 30 minutos, sendo em seguida, transferido para um liquidificador, onde foi triturado por 30 segundos. Posteriormente, o material foi filtrado em camada dupla de gaze, sendo o filtrado $(50 \mathrm{~mL})$ colocado em becker de $100 \mathrm{~mL}$ juntamente com $10 \mathrm{~mL}$ de solução de ácido tricloroacético a $25 \%$, ficando em repouso por 30 minutos. Adiante, o material foi centrifugado a $1000 \mathrm{rpm} / 15$ minutos e, no filtrado, determinado o teor de compostos nitrogenados pelo método kjeldall (Broderick, comunicação pessoal).

$\mathrm{O}$ restante do material foi submetido à pré-secagem a $55^{\circ} \mathrm{C}$ durante 72 horas e moagem em peneira de $1 \mathrm{~mm}$ de diâmetro, para posteriores análises de matéria seca (MS), compostos nitrogenados $(\mathrm{N})$, matéria mineral (MM) e extrato etéreo (EE), conforme AOAC (1990). As análises de fibra insolúvel nos detergentes neutro (FDN) e ácido (FDA) foram feitas em autoclave, conforme Pell e Schofield (1993), e lignina, conforme Van Soest et al. (1991). Os teores dos compostos nitrogenados insolúveis nos detergentes neutro (NIDN) e ácido (NIDA) foram determinados conforme Licitra et al. (1996). Os teores da proteína verdadeira solúvel em detergente neutro (PSDN ou fração $\mathrm{B}_{1}+\mathrm{B}_{2}$ ) foram obtidos a partir da seguinte expressão: $\mathrm{B}_{1}+\mathrm{B}_{2}=\mathrm{N}$ total - $(\mathrm{NNP}+$ NIDN), e da fração $B_{3}$ pela diferença entre o NIDN e o NIDA.

Os carboidratos totais (CT) foram determinados conforme Sniffen et al. (1992), sendo as suas frações: carboidratos fibrosos (CF), considerados como sendo a FDN corrigida para o seu conteúdo em cinzas e proteínas (FDNcp); carboidratos não-fibrosos (CNF) obtidos pela subtração da FDNcp dos CT; e a fração C, obtida pela FDN indigerível após 144 horas de incubação in situ. A fração $\mathrm{B}_{2}$, ou seja, fração disponível da fibra foi obtida pela diferença entre a FDNcp e a fração C.

As taxas de digestão dos $\mathrm{CNF}$ e da fração $\mathrm{B}_{2}$ dos CT foram estimadas pela técnica de produção de gases, conforme Pell e Schofield (1993), com algumas adaptações. As incubações foram realizadas em frascos de vidro com capacidade de $50 \mathrm{~mL}$, donde foram pesados aproximadamente $100 \mathrm{mg}$ de substrato. Aos frascos foram adicionados $8 \mathrm{~mL}$ de tampão de Mcdougal (Mcdougal, 1949) previamente reduzido com $\mathrm{CO}_{2}$ (pH 6,9-7,0) e $2 \mathrm{~mL}$ de inóculo, proveniente de um bovino fistulado no rúmen, filtrado em camada dupla de gaze sob aspersão de $\mathrm{CO}_{2}$. Imediatamente após, os frascos receberam tampa de borracha e lacre de alumínio e permaneceram em mesa de agitação orbital numa sala climatizada, mantida a $39^{\circ} \mathrm{C}$. As leituras de pressão foram realizadas por meio de um sensor de pressão acoplado a um voltímetro, nos seguintes tempos: 1, 2, 3, 4, 5, 6, 9, 12 , $18,24,30,36,48,60$ e 72 horas. As leituras realizadas em volts foram convertidas para $\mathrm{mL}$ de gás a partir do fator de conversão 8,7 ( 1 volt $=8,7 \mathrm{~mL}$ de gás) conforme Pell e Schofield (1993). A cinética da produção cumulativa dos gases foi analisada empregando-se o modelo logístico bicompartimental (Schofield et al., 1994):

$$
\begin{aligned}
\mathrm{V}(\mathrm{t})= & \mathrm{Vf}_{1} /\left(1+\exp \left(2-4 * \mathrm{c}_{1} *(\mathrm{~T}-\mathrm{L})\right)\right)+\mathrm{Vf}_{2} / \\
& \left(1+\exp \left(2-4 * \mathrm{c}_{2} *(\mathrm{~T}-\mathrm{L})\right)\right)
\end{aligned}
$$

em que $\mathrm{V}(\mathrm{t})$ é o volume acumulado no tempo $\mathrm{t} ; \mathrm{Vf}_{1}$, o volume de gás oriundo da fração de rápida digestão $(\mathrm{CNF}) ; \mathrm{c}_{1}\left(\mathrm{~h}^{-1}\right)$, a taxa de degradação da fração de rápida digestão $(\mathrm{CNF})$; $\mathrm{L}$, a latência; e T, o tempo (h); $\mathrm{Vf}_{2}$, o volume de gás da fração de lenta degradação $\left(\mathrm{B}_{2}\right) ; \mathrm{c}_{2}\left(\mathrm{~h}^{-1}\right)$, a taxa de degradação da fração $\mathrm{B}_{2}$.

A digestibilidade in vitro da matéria seca (DIVMS) foi determinada pelo método de dois estágios, conforme Tilley e Terry (1963) e o NDT, em nível de mantença, foi estimado conforme NRC (2001), a partir das seguintes equações:

$\mathrm{NDT}=\mathrm{CNFD}+\mathrm{PBD}+\mathrm{FDND}+\mathrm{AGD} * 2,25-7$ em que, $\mathrm{CNFD}=\mathrm{CNF}^{*} 0,98$; $\mathrm{PBD}=\mathrm{PB} * \mathrm{EXP}(-$ $1,2 *(\mathrm{PIDA} / \mathrm{PB})) ; \mathrm{FDND}=0,75 *(\mathrm{FDNp}-\mathrm{Lig}) *(1-(\mathrm{Lig} /$ FDNp)0,667).

$\mathrm{AGD}=(\mathrm{EE}-1)$ e 7 refere-se ao NDT metabólico fecal, em que CNFD representa os carboidratos nãofibrosos verdadeiramente digestíveis; PBD, a PB verdadeiramente digestível; AGD, os ácidos graxos

R. Bras. Zootec., v.32, n.5, p.1250-1258, 2003 
verdadeiramente digestíveis; FDND, a FDN digestível; Lig, a lignina.

As análises estatísticas foram conduzidas segundo o delineamento inteiramente casualizado, conforme o modelo:

$$
\mathrm{Y}_{\mathrm{ij}}=\mu+\mathrm{T}_{\mathrm{i}}+\mathrm{E}(\mathrm{i})_{\mathrm{j}}
$$

em que: $\mu=$ constante geral; $\mathrm{T}_{\mathrm{i}}=$ efeito relativo ao tratamento ou teor de panículas i, sendo $\mathrm{i}=1,2,3,4 \mathrm{e}$ 5; $\mathrm{E}(\mathrm{i})_{\mathrm{j}}=$ erro aleatório associado a cada observação, pressuposto NID $\left(0, \sigma^{2}\right)$.

As comparações entre médias foram realizadas por intermédio de análise de regressão linear, adotando-se $\alpha$ $=0,05$. A escolha de modelo se deu com base nos testes de significância para os coeficientes de regressão, no coeficiente de determinação e na ocorrência de falta de ajustamento. Os coeficientes de determinação $\left(\mathrm{r}^{2} / \mathrm{R}^{2}\right)$ foram expressos como a razão entre a soma de quadrados da regressão e a soma de quadrados total.

\section{Resultados e Discussão}

De acordo com o aspecto visual, com o odor, com o pH das silagens e com o fato de que não foi verificada putrefação em qualquer das silagens, pode-se inferir que houve fermentação satisfatória do material ensilado.
A composição bromatológica da silagem de sorgo com porcentagens crescentes de panículas é apresentada na Tabela 1, onde pode ser visualizado que os teores de matéria seca (MS), proteína bruta (PB), carboidratos não fibrosos (CNF), extrato etéreo (EE) e lignina (\% FDN) aumentaram linearmente e os teores de matéria mineral (MM), carboidratos totais (CT) e FDN reduziram com o acréscimo de panículas.

Os teores de FDN encontrados neste trabalho estão de acordo com a variação verificada por Silva et al. (1999) de 65,87 a $22,70 \%$, para as silagens de sorgo forrageiro, para as proporções de panículas de zero e $100 \%$, respectivamente.

Considerando a relação inversa entre o teor de FDN e o consumo, quando a ingestão é limitada pela repleção ruminal (Mertens, 1987, 1994), pode-se inferir que a confecção de silagens com maiores teores de panículas permitiriam mais elevados consumos. Conseqüentemente, o aumento do teor de CNF teoricamente aumentaria o conteúdo em NDT, uma vez que estes carboidratos apresentam quase completa disponibilidade nutricional para os ruminantes (Van Soest, 1967; Mertens, 1996), bem como aumentariam a exigência em proteína degradada no rúmen para o atendimento do requisito $\mathrm{em} \mathrm{N}$ dos microrganismos que fermentam estes carboidratos

Tabela 1 - Teores médios e equações de regressão para a matéria seca (MS), proteína bruta (PB), matéria mineral (MM), extrato etéreo (EE), carboidratos totais (CT), fibra insolúvel em detergente neutro (FDN), carboidratos nãofibrosos (CNF) e lignina, em função da porcentagem de panículas da silagem de sorgo (P), e respectivos coeficientes de determinação

Table 1 - Average content and regression equation (RE) for the dry matter (DM), crude protein (CP), ash, ether extract (EE), total carbohydrate (TC), neutral detergent fiber (NDF), non fiber carbohydrate (NFC) and lignin in function of panicle proportions $(P)$ and respective coefficients of determination

\begin{tabular}{|c|c|c|c|c|c|c|c|c|}
\hline \multirow[t]{2}{*}{ Itens } & \multicolumn{6}{|c|}{$\begin{array}{c}\text { Panículas (\%) } \\
\text { Panicle (\%) }\end{array}$} & \multirow[t]{2}{*}{$\begin{array}{l}\mathrm{ER} \\
R E\end{array}$} & \multirow[t]{2}{*}{$\mathrm{r}^{2}$} \\
\hline & 0 & 20 & 40 & 60 & 80 & 100 & & \\
\hline $\begin{array}{l}\mathrm{MS}(\%) \\
D M\end{array}$ & 18,37 & 25,41 & 33,18 & 40,96 & 48,73 & 59,85 & $\hat{Y}=17,38+0,4034 \mathrm{P}$ & 0,99 \\
\hline $\begin{array}{l}\mathrm{PB}^{1} \\
C P\end{array}$ & 3,22 & 5,53 & 6,87 & 8,21 & 9,56 & 9,93 & $\hat{Y}=3,87+0,0671 \mathrm{P}$ & 0,95 \\
\hline $\begin{array}{l}\mathrm{MM}^{1} \\
\text { Ash }\end{array}$ & 9,71 & 8,39 & 7,52 & 6,65 & 5,79 & 4,99 & $\hat{Y}=9,48-0,0461 \mathrm{P}$ & 0,94 \\
\hline EE1 & 3,06 & 3,35 & 3,22 & 4,30 & 3,73 & 5,57 & $\hat{Y}=2,82+0,0211 \mathrm{P}$ & 0,58 \\
\hline $\begin{array}{l}\mathrm{CT}^{1} \\
T C\end{array}$ & 84,01 & 82,71 & 82,38 & 80,82 & 80,92 & 79,50 & $\hat{Y}=83,83-0,0420 \mathrm{P}$ & 0,85 \\
\hline $\begin{array}{l}\mathrm{FDN}^{1} \\
N D F\end{array}$ & 65,22 & 58,87 & 51,13 & 43,40 & 35,67 & 24,93 & $\hat{Y}=66,45-0,3983 \mathrm{P}$ & 0,99 \\
\hline $\begin{array}{l}\mathrm{CNF}^{1} \\
N F C\end{array}$ & 20,82 & 25,95 & 33,30 & 39,36 & 47,38 & 58,38 & $\hat{Y}=19,09+0,3689 \mathrm{P}$ & 0,98 \\
\hline $\begin{array}{l}\text { Lignina }^{2} \\
\text { Lignin }\end{array}$ & 7,98 & 8,80 & 10,58 & 12,99 & 16,45 & 24,81 & $\hat{Y}=5,78+0,1564 \mathrm{P}$ & 0,83 \\
\hline
\end{tabular}

$1 \%$ na MS (\% in DM).

$2 \%$ na FDN (\% in NDF).

R. Bras. Zootec., v.32, n.5, p.1250-1258, 2003 
(Russell et al., 1992).

Considerando que a quantidade de lignina (\% na MS) não foi alterada com o acréscimo de panículas e que o teor de FDN foi reduzido, a porcentagem de lignina na FDN foi aumentada em função da adição de panículas à silagem, ao contrário do observado para o comportamento da lignina em função da adição de grãos à silagem de milho (Cabral, 2002). Embora Haslan (1989), citado por Van Soest (1994), defina os taninos como compostos fenólicos solúveis em água e supostamente é aceito que estes compostos são solubilizados mediante hidrólise ácida, alguns tipos de taninos (condensados) podem formar precipitados, quando são polimerizados ao complexo protéico, tornando-se insolúveis e aumentando o teor de lignina em detergente ácido (Van Soest, 1994). Desta forma, pode-se inferir que a adição de panículas à silagem de sorgo aumentou a concentração em taninos, uma vez que a lignina está associada aos polímeros da parede celular vegetal, cujo teor foi reduzido, conforme redução do teor de FDN.

Silva et al. (1999) avaliaram silagens de diferentes variedades de sorgo com o aumento da porcentagem de panículas e observaram que, em geral, houve aumento da concentração de fenóis totais com o acréscimo de panículas. Considerando que os taninos ocorrem somente nas camadas do pericarpo (Watterson \& Butler, 1983), o aumento da concentração destes compostos com a adição de panículas seria esperado.

$\mathrm{Na}$ Tabela 2, são apresentadas as frações nitrogenadas para a silagem de sorgo, onde nota-se que, embora tenha havido aumento da porcentagem de NNP com a adição de panículas, esta fração atingiu o valor máximo de $21 \%$ do $\mathrm{N}$ total, cujo valor é bem inferior aos $50,67 \%$ verificados para a mesma fração do $\mathrm{N}$ total para a silagem de milho, quando foram adicionados $30 \%$ de grãos (50\% de espigas). Deste comportamento para o NNP da silagem de sorgo, pode-se sugerir que houve resistência da $\mathrm{PB}$ à hidrólise durante a fermentação, provavelmente exercida pela presença de taninos, que por estarem ligados à matriz protéica, tendem a reduzir a proteólise da massa ensilada. Esta característica seria altamente desejável, uma vez que a produção de $\mathrm{N}-\mathrm{NH}_{3}$ (nos silos) está associada à fermentação de aminoácidos da $\mathrm{PB}$ do alimento ensilado e às elevadas perdas de compostos nitrogenados $(\mathrm{N})$.

A adição de panículas reduziu linearmente a porcentagem das frações NIDN e NIDA, as quais são consideradas relativamente resistentes à digestão e indigerível, respectivamente. Portanto, o aumento de panículas na silagem de sorgo promoveu acréscimo da proporção de proteínas do grão, as quais são teoricamente mais susceptíveis à hidrólise. Dessa forma, pode-se deduzir que o aumento do NNP na silagem de sorgo foi limitado pela presença de taninos. A redução do NIDA aumentaria a disponibilidade de $\mathrm{N}$ no rúmen, bem como nos intestinos. Entretanto, a fração $B_{1}+B_{2}$ é a principal fração, independentemente da adição de panículas.

As frações dos carboidratos totais são apresentadas na Tabela 3, na qual pode ser notado que a adição de panículas aumentou linearmente o teor de CNF, expresso em $\mathrm{g} / \mathrm{kg}$ de MS, mas não teve efeito sobre a fração $\mathrm{C}$, pois a fração disponível da fibra $\left(\mathrm{B}_{2}\right)$ foi reduzida até atingir $0 \%$ dos $\mathrm{CT}$. Este comportamento

Tabela 2 - Valores médios e equação de regressão para os compostos nitrogenados não-protéicos (NNP), frações $B_{1}+B_{2}, B_{3}$ e $C$ e compostos nitrogenados insolúveis em detergente neutro (NIDN) na silagem de sorgo, em função da porcentagem de panículas $(P)$, e respectivos coeficientes de determinação

Table 2 - Average content and regression equation (RE) for non-protein nitrogen (NPN), $B_{1}+B_{2}, B_{3}$ and $C$ fractions and neutral detergent insoluble nitrogen (NDIN) in sorghum silage in function of panicle porcentage $(P)$ and respective coefficients of determination

\begin{tabular}{|c|c|c|c|c|c|c|c|c|}
\hline \multirow[t]{2}{*}{$\begin{array}{l}\text { Frações } \\
\text { Fractions }\end{array}$} & \multicolumn{6}{|c|}{$\begin{array}{c}\text { Panículas (\%) } \\
\text { Panicle (\%) }\end{array}$} & \multirow[t]{2}{*}{$\begin{array}{l}\mathrm{ER} \\
\mathrm{RE}\end{array}$} & \multirow[t]{2}{*}{$r^{2}$} \\
\hline & 0 & 20 & 40 & 60 & 80 & 100 & & \\
\hline $\begin{array}{l}\mathrm{NNP}^{1} \\
N P N\end{array}$ & 9,19 & 12,45 & 13,58 & 17,14 & 19,00 & 21,24 & $\hat{Y}=9,48+0,1192 \mathrm{P}$ & 0,92 \\
\hline $\begin{array}{l}\mathrm{B}_{1}+\mathrm{B}_{2}{ }^{1} \\
\mathrm{NIDNN}^{1} \\
N D I N\end{array}$ & $\begin{array}{l}75,98 \\
14,83\end{array}$ & $\begin{array}{l}74,49 \\
13,05\end{array}$ & $\begin{array}{l}74,34 \\
12,07\end{array}$ & $\begin{array}{l}71,77 \\
11,08\end{array}$ & $\begin{array}{l}70,90 \\
10,10\end{array}$ & $\begin{array}{l}67,63 \\
11,13\end{array}$ & $\begin{array}{l}\hat{Y}=76,45-0,0787 \mathrm{P} \\
\hat{Y}=14,07-0,0405 \mathrm{P}\end{array}$ & $\begin{array}{l}0,81 \\
0,78\end{array}$ \\
\hline $\mathrm{B}_{3}^{1}$ & 3,85 & 4,10 & 4,29 & 4,48 & 4,68 & 6,09 & $\hat{Y}=3,65+0,0184 \mathrm{P}$ & 0,76 \\
\hline $\mathrm{C}^{1}$ (NIDA) & 10,98 & 8,96 & 7,78 & 6,60 & 5,42 & 5,09 & $\hat{Y}=10,41-0,0590 \mathrm{P}$ & 0,95 \\
\hline
\end{tabular}

$1 \%$ no $\mathrm{N}$ total (\% of total $\mathrm{N}$ ).

R. Bras. Zootec., v.32, n.5, p.1250-1258, 2003 
Tabela 3 - Valores médios e equações de regressão para os carboidratos não-fibrosos (CNF) e frações $B_{2}$ e $C$ da silagem de sorgo, em função da porcentagem de panículas $(P)$, e respectivos coeficientes de determinação Table 3 - Average content and regression equation (RE) for non fiber carbohydrate (NFC) and B2 and C fractions of sorghum silage, in function of panicle porcentage $(P)$ and respective coefficients of determination

\begin{tabular}{|c|c|c|c|c|c|c|c|c|}
\hline \multirow[t]{2}{*}{ Itens } & \multicolumn{6}{|c|}{$\begin{array}{c}\text { Panículas (\%) } \\
\text { Panicle (\%) } \\
\end{array}$} & \multirow[t]{2}{*}{$\begin{array}{l}\mathrm{ER} \\
R E\end{array}$} & \multirow[t]{2}{*}{$\mathrm{r}^{2}$} \\
\hline & 0 & 20 & 40 & 60 & 80 & 100 & & \\
\hline \multicolumn{9}{|c|}{$\begin{array}{l}\% \text { dos carboidratos totais } \\
\% \text { of total carbohydrate }\end{array}$} \\
\hline $\begin{array}{l}\mathrm{CNF} \\
\mathrm{NFC}\end{array}$ & 24,78 & 31,36 & 40,42 & 48,70 & 58,45 & 70,92 & - & - \\
\hline $\mathrm{B}_{2}$ & 45,40 & 41,26 & 30,53 & 29,71 & 12,40 & 0 & - & - \\
\hline \multicolumn{9}{|c|}{$\begin{array}{c}\mathrm{g} / \mathrm{kg} \text { de } \mathrm{MS} \\
\mathrm{g} / \mathrm{kg} \text { of } D M\end{array}$} \\
\hline $\begin{array}{l}\mathrm{CNF} \\
N F C\end{array}$ & 208,18 & 259,46 & 332,99 & 393,64 & 473,86 & 564,07 & $\hat{Y}=194,65+3,55 \mathrm{P}$ & 0,94 \\
\hline $\mathrm{B}_{2}$ & 381,29 & 341,19 & 251,49 & 240,14 & 100,29 & 0 & $\hat{Y}=407,50-3,75 \mathrm{P}$ & 0,94 \\
\hline $\mathrm{C}^{2}$ & 250,55 & 226,50 & 239,31 & 174,47 & 235,05 & 230,96 & $\hat{Y}=226,14$ & - \\
\hline
\end{tabular}

difere drasticamente do observado para as frações de carboidratos na silagem de milho em função da adição de grãos (Cabral, 2002). Uma vez que a fração C foi obtida in situ e também in vitro, sendo considerada como a FDN indigerível após 144 horas de incubação no rúmen ou na presença de microrganismos do rúmen, a sua não alteração com a adição de panículas à silagem, é um forte indício do efeito dos taninos sobre a digestão dos constituintes da parede celular vegetal. Embora os taninos, normalmente estejam associados à proteína, o aumento da sua concentração no meio pode limitar a digestão dos carboidratos, uma vez que tem sido sugerido que estes compostos inibiriam os microrganismos fibrolíticos, reduzindo suas estruturas de adesão ao substrato.

$\mathrm{Na}$ Tabela 4, são apresentadas as taxas de digestão da fração $\mathrm{B}_{2}$ e CNF, bem como o volume final de gás, a digestibilidade in vitro da matéria seca (DIVMS) e o NDT estimado. A taxa de digestão dos CNF não foi afetada pela adição de panículas, e a taxa da fração $\mathrm{B}_{2}$ aumentou linearmente. Embora para os CNF tenha sido estimada taxa de digestão média de $0,1469 \mathrm{~h}^{-1}$, esta é bem inferior à estimada para a silagem de milho. Entretanto, não se pode concluir que estas são inerentes desta fração na silagem de sorgo, ou se são resultado do efeito inibitório dos taninos sobre a hidrólise destes carboidratos.

A adição de panículas aumentou o teor de CNF (Tabela 3), mas o volume final de gás não foi afetado e a DIVMS apresentou valor máximo de 69,52\% para a silagem com $60,10 \%$ de panículas. Tal fato desperta curiosidade, mas pode ser explicado em virtude da inalterada fração $\mathrm{C}$ com o acréscimo de panículas e, adicionalmente, especula-se que até mesmo a digestão dos CNF tenha sido retardada pela presença de taninos, comportamento este não verificado para a silagem de milho (Cabral, 2002). Embora, para o caso da produção cumulativa de gás, em particular, o volume final de gás possa ser influenciado pelas diferentes rotas fermentativas e estequiometria das reações exercidas pelos microrganismos do rúmen em função da variação nos carboidratos do meio (Beuvink e Spoelstra, 1992), seria esperado aumento linear da produção de gás em função do acréscimo de panículas à silagem, conforme observado para a silagem de milho.

Silva et al. (1999) observaram aumento linear da DIVMS com o aumento da porcentagem de panículas na silagem de sorgo, com um $\mathrm{r}^{2}$ de 0,92 e $\mathrm{b}_{1}$ de 0,25 , cujos resultados são bem diferentes dos observados no presente estudo.

Considerando que a principal alteração na silagem de sorgo pela adição de panículas foi o aumento dos $\mathrm{CNF}$, os quais apresentam disponibilidade constante e elevada entre e dentre os alimentos $(\sim 98 \%)$, era esperado o aumento na DIVMS e do volume final de gás e NDT com o aumento destes compostos. Entretanto, não foi verificado aumento do volume de gás e a DIVMS apresentou comportamento quadrático,

R. Bras. Zootec., v.32, n.5, p.1250-1258, 2003 
como pode ser visualizado nas Figuras 1 e 2.

Os taninos são geralmente relacionados à redução da digestibilidade da PB e da fibra (Mcsweeney et al., 2001). Devido à sua habilidade de complexação, os taninos são altamente reativos com a parede celular microbiana, bem como enzimas extracelulares, o que, por sua vez, inibe o transporte de nutrientes e retarda o crescimento microbiano e, conseqüentemente, afeta a digestão dos carboidratos constituintes da parede

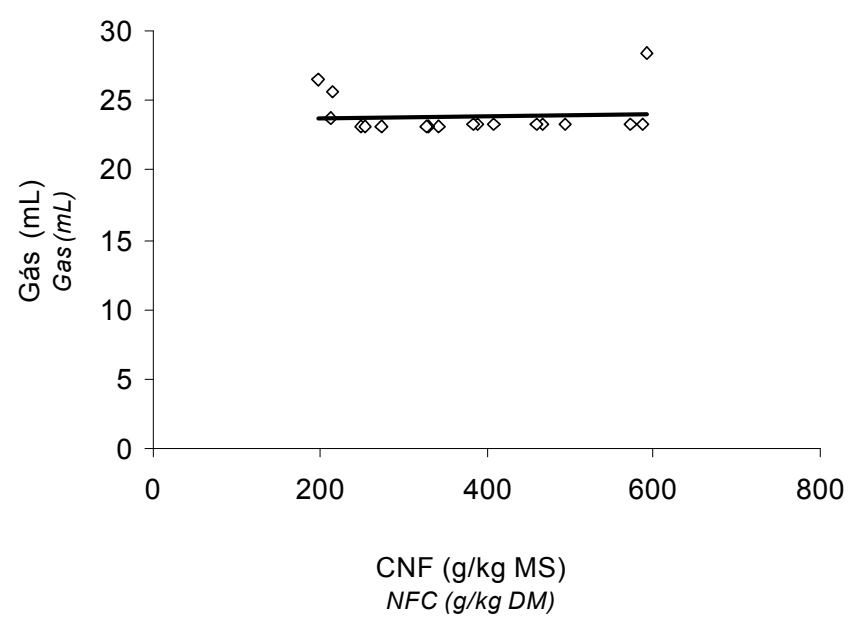

Figura 1 - Estimativa do volume de gás, em função das concentrações de carboidratos não fibrosos $(\mathrm{CNF})(\mathrm{Y}=23,83)$.

Figure 1 - Estimative of total gas production in function of content of non fiber carbohydrates.

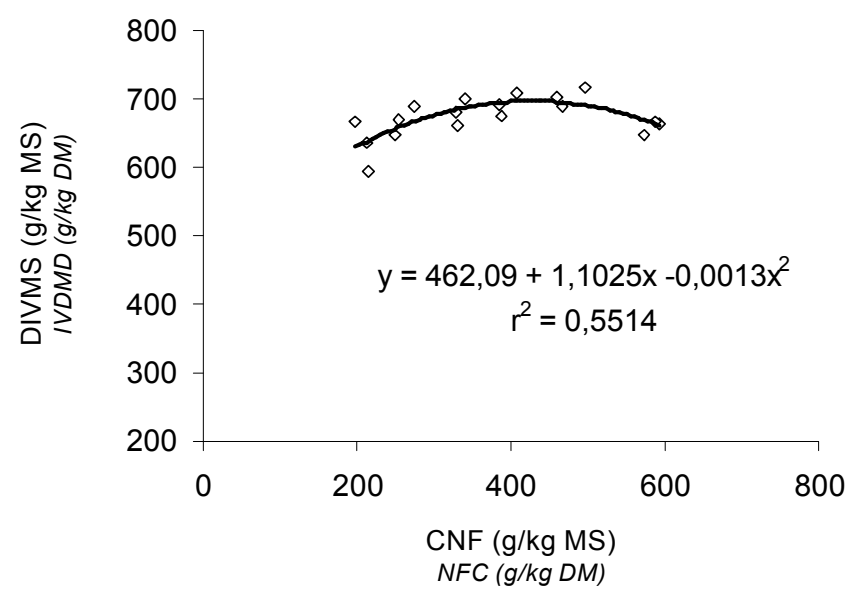

Figura 2 - Estimativa da digestibilidade in vitro da matéria seca (DIVMS) em função dos teores de carboidratos não fibrosos (CNF).

Figure 2 - Estimative of the IVDMD in function of content of non fiber carbohydrates. celular vegetal (Mcsweeney et al., 2001). Entretanto, como o teor de FDN para as silagens de elevado teor de panículas era relativamente baixo, pode-se inferir que houve efeito dos taninos sobre a digestão dos CNF.

Adicionalmente, a ausência de FDN disponível (fração $B_{2}$ ) para a silagem de sorgo com a maior porcentagem de panículas contribui para a redução da DIVMS e do volume de gás em resposta ao aumento de panículas.

$\mathrm{Na}$ Tabela 4 e Figura 3, são apresentados os teores de nutrientes digestíveis totais (NDT) estimados em função da porcentagem de panículas e, observa-se que houve aumento linear $\left(\mathrm{r}^{2}=0,97\right)$. Entretanto, como observado para a relação entre a porcentagem de panículas e o volume final de gás ou a DIVMS, pode-se inferir que a estimação do NDT a partir da composição química (NRC, 2001), poderia superestimar a disponibilidade de energia de silagens de sorgo com elevado teor de panículas, conforme comportamento da DIVMS ou gás e NDT estimado, pois estas equações não prevêem os efeitos de compostos secundários, tais como os taninos.

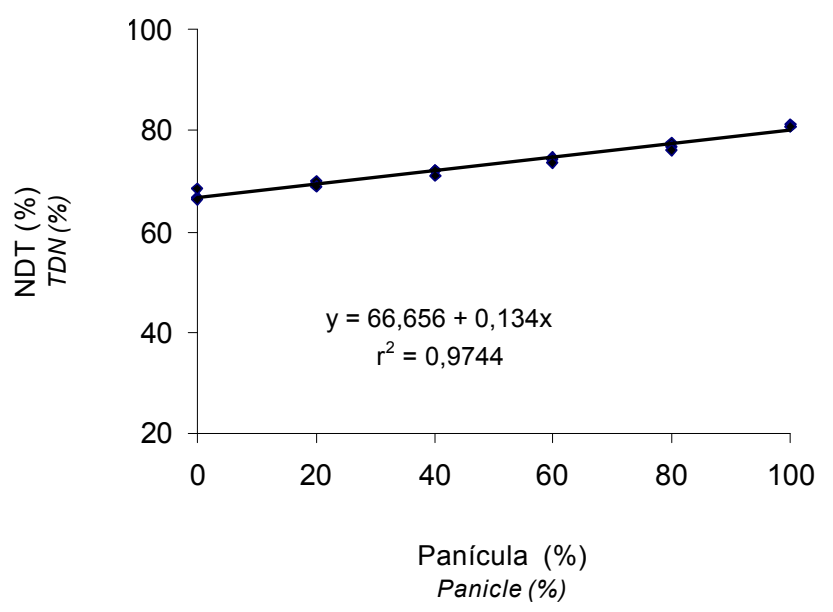

Figura 3 - NDT estimado utilizando as equações do NRC (2001), em função da porcentagem de panículas na silagem de sorgo.

Figure 3 - TDN estimated by NRC (2001) equations in function of panicle proportions for sorghum silage.

R. Bras. Zootec., v.32, n.5, p.1250-1258, 2003 
Tabela 4 - Valores médios e equações de regressão para as taxas de digestão $\left(\mathrm{h}^{-1}\right)$ da fração $\mathrm{B}_{2}$ e carboidratos nãofibrosos (CNF), volume final de gás (VT), em $\mathrm{mL}$, digestibilidade in vitro da matéria seca (DIVMS) e NDT estimado (\%) para a silagem de sorgo, em função da porcentagem de panículas $(P)$, e respectivos coeficientes de determinação

Table 4 - Average content and regression equation (RE) for the digestion rate of $B_{2}$ fraction and non fiber carbohydrate (NFC), gas production (GP), in vitro dry matter digestibility (IVDMD), estimated TDN for sorghum silage, in function of panicles porcentage $(P)$, and respective coefficients of determination

\begin{tabular}{|c|c|c|c|c|c|c|c|c|}
\hline \multirow[t]{2}{*}{$\begin{array}{l}\text { Frações } \\
\text { Fractions }\end{array}$} & \multicolumn{6}{|c|}{$\begin{array}{c}\text { Panículas (\%) } \\
\text { Panicles (\%) }\end{array}$} & \multirow[t]{2}{*}{$\begin{array}{l}\mathrm{ER} \\
R E\end{array}$} & \multirow[t]{2}{*}{$\mathrm{r}^{2}$} \\
\hline & 0 & 20 & 40 & 60 & 80 & 100 & & \\
\hline $\begin{array}{l}\mathrm{CNF} \\
N F C\end{array}$ & 0,1358 & 0,1422 & 0,1469 & 0,1516 & 0,1563 & 0,1486 & $\hat{Y}=0,1469$ & - \\
\hline $\begin{array}{l}\mathrm{B}_{2} \\
\mathrm{VT}\end{array}$ & 0,0247 & 0,0255 & 0,0265 & 0,0276 & 0,0286 & - & $\hat{Y}=0,0246+0,000049 \mathrm{P}$ & 0,29 \\
\hline GP & 25,26 & 23,09 & 23,16 & 23,23 & 23,31 & 24,95 & $\hat{Y}=23,83$ & - \\
\hline $\begin{array}{l}\text { DIVMS } \\
I V D M D\end{array}$ & 63,27 & 66,82 & 68,00 & 69,19 & 70,38 & 65,95 & $\hat{Y}=63,09+0,2141 \mathrm{P}-0,001781 \mathrm{P}^{2}$ & 0,56 \\
\hline $\begin{array}{l}\text { NDT1 } \\
T D N\end{array}$ & 67,07 & 69,43 & 71,74 & 74,17 & 76,79 & 80,92 & $\hat{Y}=66,66+0,1340 \mathrm{P}$ & 0,97 \\
\hline
\end{tabular}

${ }^{1}$ Estimado pelas equações do NRC (2001) (Estimated by NRC [2001] equations).

\section{Conclusões}

O acréscimo de panículas à silagem de sorgo resultou em aumento dos carboidratos não fibrosos, mas não influenciou a fração indigestível da fibra.

A adição de panículas não afetou o volume final de gás.

A estimação do NDT a partir das equações do NRC (2001) parece não ser adequada para a silagem de sorgo.

\section{Literatura Citada}

ASSOCIATION OF OFFICIAL ANALYTICAL CHEMISTS AOAC. Official methods of analysis. 15.ed., Arlington, 1990. $1117 \mathrm{p}$.

BEUVINK, J.M.W.; SPOELSTRA, S.F. Interactions between substrate, fermentation end-products, buffering systems and gas production upon fermentation of different carbohydrates by mixed rumen microorganisms in vitro. Applied Microbiology and Technology, v.37, n.4, p.505-509, 1992. BROCK, T.D.; MADIGAN, M.T.; MARTINKO, J.M. et al. Biology of microorganisms. 7.ed. Englewood Cliffs, New Jersey: Prentice-Hall International, 1994. 909p.

CABRAL, L.S. Avaliação de alimentos para ruminantes por intermédio de métodos in vivo e in vitro. Viçosa, MG: Universidade Federal de Viçosa, 2002. 137p. Tese (Doutorado em Zootecnia) - Universidade Federal de Viçosa, 2002.

LEHNINGER, A.L.; NELSON, D.L.; COX, M.M. Principles of biochemistry. 2.ed. New York: Worth Publishers, 1993. $1013 \mathrm{p}$.

LICITRA, G.; HERNANDEZ, T.M.; Van SOEST, P.J. Standardization of procedures for nitrogen fractionation of ruminant feeds. Animal Feed Science and Technology, v.57, n.4, p.347-358, 1996.

R. Bras. Zootec., v.32, n.5, p.1250-1258, 2003
McDOUGAL, E.I. Studies on ruminal saliva. 1. The composition and output of sheep's saliva. Biochemical Journal, v.43, n.1, p.99-109, 1949.

McSWEENEY, C.S.; PALMER, B.; McNEILL, D.M. et al. Microbial interactions with tannins: Nutritional consequences for ruminants. Animal Feed Science and Technology, v.91, p.83-93, 2001.

MERTENS, D.R. Predicting intake and digestibility using mathematical models of ruminal function. Journal of Animal Science, v.64, n.5, p.1548-1558, 1987.

MERTENS, D.R. Regulation of forage intake. In: FAHEY JR., G.C. (Ed.). Forage quality, evaluation, and utilization. Madison: American Society of Agronomy, 1994. p.450-493.

MERTENS, D.R. Using fiber and carbohydrate analyses to formulate dairy rations. In: INFORMATIONAL CONFERENCE WITH DAIRY AND FORAGES INDUSTRIES, 1996, Wisconsin. Proceedings... Wisconsin: 1996.

NATIONAL RESEARCH COUNCIL - NRC. Nutrients requirements of dairy cattle. 7.ed. Washington, D.C.: National Academy Press, 2001. 381p.

PELL, A.N.; SCHOFIELD, P. Computerized monitoring of gas production to measure forage digestion in vitro. Journal of Dairy Science, v.76, n.9, p.1063-1073, 1993.

RUSSELL, J.B.; O'CONNOR, J.D.; FOX, D.G. et al. A net carbohydrate and protein system for evaluation cattle diets: ruminal fermentation. Journal of Animal Science, v.70, n.12, p.3551-3581, 1992.

SCHOFIELD, P.; PITT, R.E.; PELL, A.N. Kinetics of fiber digestion from in vitro gas production. Journal of Animal Science, v.72, n.11, p.2980-2991, 1994.

SILVA, F.F.; GONÇALVES, L.C.; RODRIGUES, J.A.S. et al. Qualidade de silagens de híbridos de sorgo (Sorghum bicolor (L.) Moench) de portes baixo, médio e alto com diferentes proporções de colmo+folhas/panícula. 2. Avaliação do valor nutritivo. Revista Brasileira de Zootecnia, v.28, n.1, p.21-29, 1999. 
SNIFFEN, C.J.; O’CONNOR, D.J.; VAN SOEST, P.J. et al. A net carbohydrate and protein system for evaluating cattle diets: carbohydrate and protein availability. Journal of Animal Science, v.70, n.12, p.3562-3577, 1992.

TILLEY, J.M.A.; TERRY, R.A. A two-stage technique for the in vitro digestion of forage crops. Journal British Grassland Society, v.18, p.104-111, 1963.

Van SOEST, P.J. Development of a comprehensive system of feeds analysis and its applications to forages. Journal of Animal Science, v.26, p.119-128, 1967.

Van SOEST, P.J.; ROBERTSON, J.B.; LEWIS, B.A. Methods for dietary fiber, neutral detergent fiber, and nonstarch polyssacarides in relation to animal nutrition. Journal of Dairy Science, v.74, n.10, p.3583-3597, 1991.

Van SOEST, P.J. Nutritional ecology of the ruminant. 2.ed. Ithaca: Cornell University Press, 1994. 476p.
WATTERSON, J.J.; BUTLER, L.G. Ocurrence of an unusual leucoanthocyanidin and absence of proanthocyanidins in sorghum leaves. Journal Agricultural Food Chemical, v.31, n.1, p.41-45, 1983.

ZAGO, C.P.; CRUZ, M.E.; GOMIDE, J.A. Avaliação do desempenho de vacas leiteiras alimentadas com silagem de milho e sorgo. In: REUNIÃO ANUAL DA SOCIEDADE BRASILEIRA DE ZOOTECNIA, 26., Porto Alegre, 1989. Anais... Porto Alegre: Sociedade Brasileira de Zootecnia, 1989. p.290.

Recebido em: 29/01/02

Aceito em: 06/01/03 